Int. J. Dev. Biol. 63: 203-215 (2019)

https://doi.org/10.1387/ijdb.180379ib

\title{
Test-tube embryos - mouse and human development in vitro to blastocyst stage and beyond
}

\author{
NIRAIMATHI GOVINDASAMY, BINYAMIN DUETHORN, HATICE O. OEZGUELDEZ, \\ YUNG S. KIM and IVAN BEDZHOV* \\ Embryonic Self-Organization research group, Max Planck Institute for Molecular Biomedicine, Münster, Germany
}

\begin{abstract}
Mammalian embryogenesis is intrauterine and depends on support from the maternal environment. Therefore, in order to directly study and manipulate early mouse and human embryos, fine-tuned culture conditions have to be provided to maintain embryo growth in vitro. Over time, the establishment and implementation of embryo culture methods have come a long way, initially enabling the development of few pre-implantation stages, expanding later to support in vitro embryogenesis from fertilization until blastocyst and even ex utero development beyond the implantation stages. Designing culture conditions that enable near physiological development of early embryos without maternal input, especially during the peri- and post-implantation stages, requires overcoming numerous experimental challenges, and it is still far from optimal. Nevertheless, embryo culture methods are an essential cornerstone of both assisted reproductive technologies and basic research, and these methods provide a platform to understand life's greatest miracle the development of a new organism.
\end{abstract}

KEY WORDS: in vitro culture, embryo, mouse blastocyst, human blastocyst, implantation

\section{Introduction}

Earth is the only planet in our solar system that can sustain surface water in a liquid phase, a fundamental prerequisite for the emergence of terrestrial life forms. In many vertebrates, such as fish and amphibians, water is the environment where external fertilization and embryonic development take place. Colonization of the land resulted in evolutionary adaptations protecting the eggs from mechanical damage and dehydration: solid shell encapsulation and the eggs' rich nutrient reserve facilitated self-sufficient embryo development until hatching. Evolution of live birth in some species of Squamata (lizards and snakes) enabled foetal development inside the female reproductive tract via the establishment of an embryo-maternal interface, the placenta. Placentation allows the exchange of nutrients, gases and waste between the maternal tissues and the developing embryo, and it is common in all mammals, with the exception of monotremes (platypus and echidnas), which lay eggs. Marsupials (kangaroos and opossums) have a placenta that exists only in the short term, until the birth of a foetus-like pup that continues its development externally, in the pouch, whereas Eutherian mammals (such as primates and rodents) have a much longer gestation period, such that when it emerges into the external world, the newborn is completely developed (Luo et al., 2011, O'Leary et al., 2013a).
In all viviparous species, theembryo's dependence on the maternal environment prohibits direct studies of embryogenesis; therefore, fine-tuned culture conditions have to be provided to support embryo growth in vitro. At the current state of technology, it is still only in science fiction that one can initiate mammalian embryogenesis in vitro from fertilization and achieve complete foetal development. However, restricted periods of embryogenesis can now be faithfully recapitulated outside of the maternal environment, particularly the pre-implantation phase of both mouse and human embryos, where culture protocols are streamlined and routinely used. A major challenge is supporting embryo development during the transition from pre- to post-implantation stages without maternal input, as well as during later stages in the absence of functional placenta. Here, we will briefly take a look at the in vitro development of pre-implantation embryos and later focus mainly on the advances and limitations of

\footnotetext{
Abbreviations used in this paper: ART, assisted reproductive technology; bFGF, basic fibroblast growth factor; CS, calf serum; ExM, extraembryonic mesoderm; FCS, foetal calf serum; FGFR, fibroblast growth factor receptor; HCS, human cord serum; hESC, human embryonic stem cells; ICM, inner cell mass, ; ITS-X, insulintransferrin-selenium-ethanolamine; IVC, in vitro culture medium; IVF, in vitro fertilization; KSR, knock-out serum replacement; LE, luminal epithelium; MEFs, mouse embryonic fibroblasts; NK, natural killer (cells); PE, primitive endoderm; PGD, preimplantation genetic diagnosis; PICMI, post-ICM intermediate; RS, rat serum; TE, trophectoderm; TGC, trophoblast giant cells, ; UPA, ulipristal acetate.
}

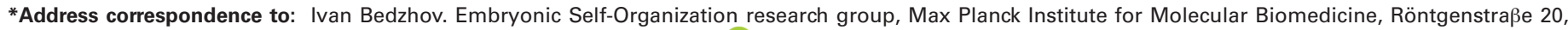
48149 Münster, Germany. E-mail: ivan.bedzhov@mpi-muenster.mpg.de - (iD https://orcid.org/0000-0002-2122-6485 
different peri- and post-implantation mouse and human embryo culture approaches.

\section{Pre-implantation development - from fertilized egg to blastocyst}

The house mouse is the preferred model organism for biomedical research, and, conclusively, we have a better understanding of murine biology than of our own. As mouse and human early embryogenesis share many parallels, mouse embryos are not only a subject of basic research but are also implemented used in applied studies, such as testing human embryo culture media (Ainsworth et al., 2017, Vijayakumar et al., 2009) and establishing methods that aim to predict embryo viability and the success rate of human-assisted reproduction (Ajduk et al., 2011, Yanez and Camarillo, 2017). But, as Mus musculus and Homo sapiens are different species, not all aspects of early mouse development

A

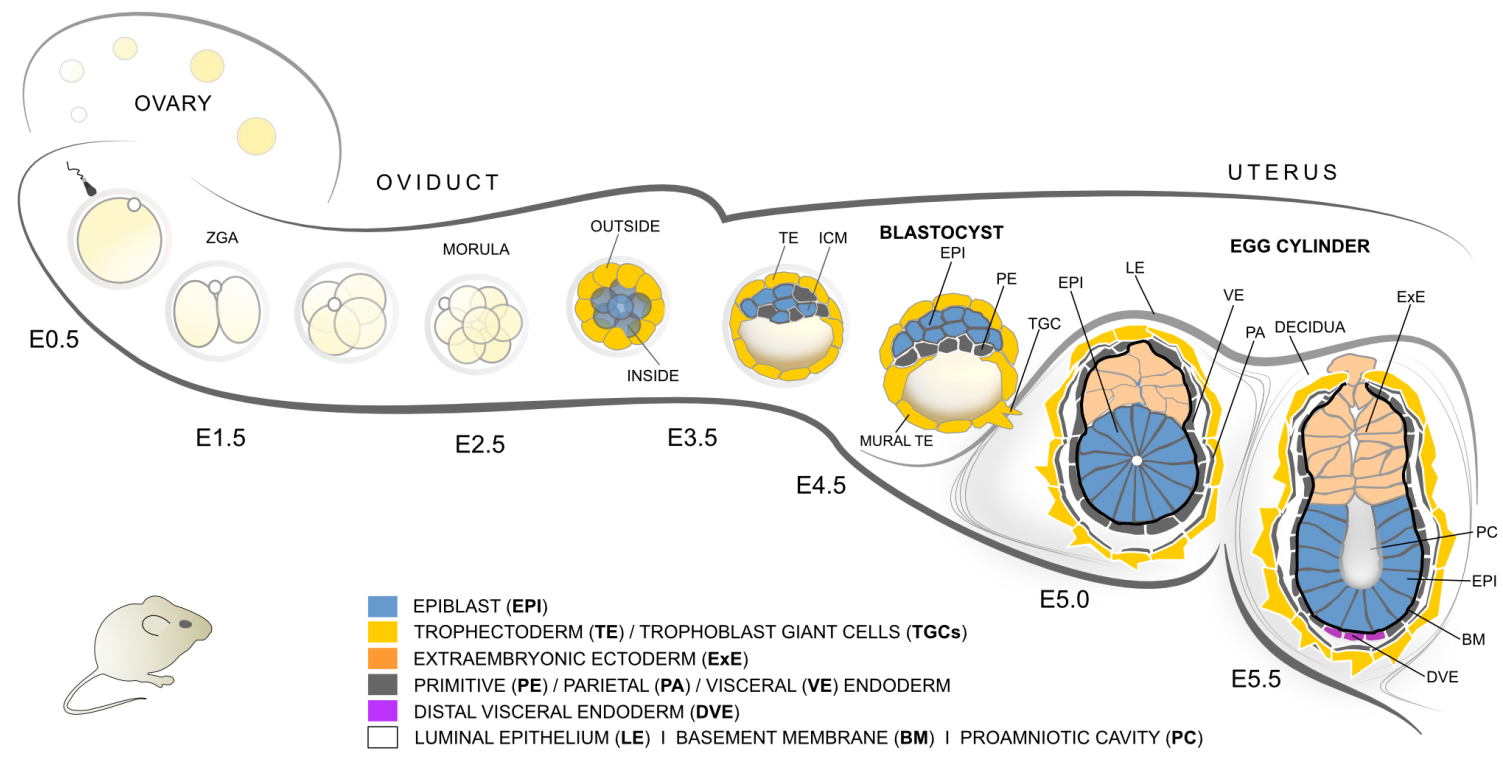

B

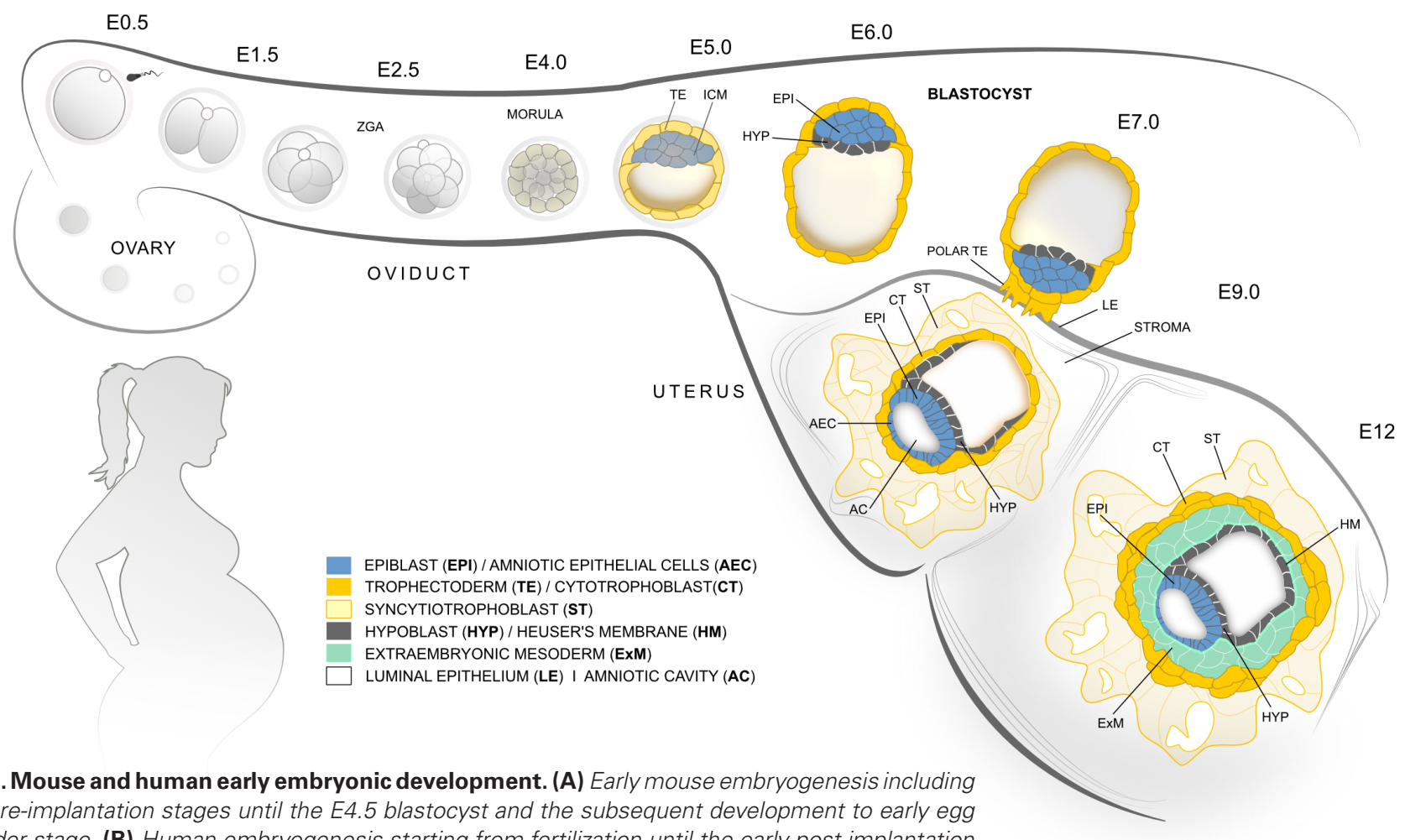

the pre-implantation stages until the E4.5 blastocyst and the subsequent development to early egg cylinder stage. (B) Human embryogenesis starting from fertilization until the early post-implantation stages, before initiation of gastrulation. 
are directly applicable to humans. The pre-implantation phase of embryo development takes four and a half days in mice and six days in humans (Fig. 1A,B). In both species, the zygote undergoes several rounds of cleavage divisions, generating progressively smaller daughter cells (blastomeres), without an overall increase of the total cell volume. During the initial divisions, transcription of the zygotic genome commences in a process known as zygotic genome activation, with a major peak at 2-cell stage in mice and 4- to 8-cell stage in humans (Braude et al., 1988, Hamatani et al., 2004). The first noticeable morphological change in the embryo takes place at late 8-cell stage in mice and 8- to 16-cell morula in humans, when the blastomeres adhere tightly (morula compaction) and establish defined apical and basolateral membrane domains (polarization) (Vestweber and Kemler, 1984). Here, as a result of asymmetric divisions and cell engulfment, the first two types of cells are specified - outside cells that inherit the apical domain and inside cells that remain non-polarized. In mice, differential activity of the Hippo and Notch signalling pathways upregulates the core trophectoderm (TE) transcription factor Cdx2 in the outside cells, whereas expression of pluripotency-associated factors, such as Sox2, are restricted to the inner cell mass (ICM) (Nishioka et al., 2009, Rayon et al., 2014, Wicklow et al., 2014). Cdx2 expression in the human embryo is not detectable before the blastocyst stage, suggesting that alternative signalling cascades and downstream transcription factors might be involved in the first lineage segregation (reviewed in Wamaitha and Niakan, 2018). Later, the TE will give rise to the embryonic portion of the placenta, whereas the ICM further segregates into two lineages - epiblast (EPI) cells that will form all tissues of the foetus and the primitive endoderm $(\mathrm{PE})$ that contributes to extraembryonic membranes. In mice, the EPI / PE cell fate decision is controlled by FGFR (fibroblast growth factor receptor) I and II signalling (Molotkov et al., 2017), whereas in humans the molecular mechanisms of the second lineage segregation are still elusive.

\section{Culture of mouse pre-implantation embryos}

Gaining a deeper understanding of both mouse and human pre-implantation development can directly help increase the success rates of assisted reproductive technologies (ART), such as pre-implantation genetic diagnosis and in vitro fertilization (IVF). A broad range of experimental techniques such as embryo micromanipulations, genetic and genome engineering methods, live imaging and next generation sequencing analyses were first established in the mouse system and then gradually made their way into the field of human embryology. None of this would have been feasible without robust protocols for growing pre-implantation embryos in vitro.

The first reported attempts of culturing mouse embryos were only successful in supporting development from 8-cell to blastocyst stage; the earlier embryos halted their development at 2-cell stage. The initial media were based on physiological saline solution with added hen egg white and yolk (Hammond, 1949) and Krebs-Ringer bicarbonate buffer supplemented with glucose, penicillin G, streptomycin and bovine serum albumin (Whitten, 1956). To overcome the 2-cell stage block, simplex optimised medium (SOM) was designed and further supplemented with increased concentrations of $\mathrm{KCl}$ and $\mathrm{NaCl}$, establishing the basic KSOM medium (potassiumsupplemented SOM). This medium that was further supplemented with Eagle's essential and non-essential amino acids (KSOM $\left.{ }^{\mathrm{AA}}\right)$.
Pyruvate was also included, as the energy metabolism of early cleavage embryos depends on oxidative phosphorylation for ATP (adenosine triphosphate) production, while glycolysis is utilized at later stages (Leese, 2012). These multiple optimizations of the KSOM culture medium resulted in high rates of zygote development into properly organized, expanded blastocysts (Ho et al., 1995, Lawitts and Biggers, 1993). Although other media such as M16 (Whittingham, 1971) and its HEPES-buffered modification M2 are still used for particular applications such as embryo flushing, KSOM became widely adopted, standardizing mouse embryo culture conditions and improving experimental reproducibility.

\section{Culture of human pre-implantation embryos}

In the 199070s, human embryos were cultured for the first time from a zygote to the 8- or 16-cells stage by using available mouse and rabbit media or regular tissue culture medium (Edwards et al., 1970). Later, the culture was extended to blastocyst stage using Ham's F10 media supplemented with foetal calf serum (FCS) or a combination of FCS and human serum (Steptoe et al., 1971). This paved the way for the pioneering work of Steptoe and Edwards that resulted in the first IVF or "test-tube" baby (Edwards, 1981). Embryo culture after IVF was performed at an atmosphere of $5 \%$ $\mathrm{O}_{2}, 5 \% \mathrm{CO}_{2}$ and $90 \% \mathrm{~N}_{2}$, as it was previously shown that hypoxic conditions increase the efficiency of mouse zygotes development to blastocyst stage (Whitten, 1971). This is in accord with the low physiological concentration of oxygen (3-5\%) found in the uterus (Ufer, 2011).

Depending on the commercial provider of media, human embryo culture procedures are usually performed following either a two-step protocol (sequential cultivation in two different media, before and after 8-cell stage) or following a less common one-step methodology (uninterrupted culture from zygote to blastocyst stage). The first embryo transfers to patients were typically carried out after 2-3 days of culture (4- to 8-cell stage), but later methods extended the culture to blastocyst stage. This allowed a visual estimation of blastocyst quality, including continuous capture by time-lapse microscopy and preselection of the "fittest" embryos for transfer. The extended culture enabled IVF clinicians to implement additional techniques such as pre-implantation genetic diagnosis via blastomere biopsy and assisted hatching, which altogether result in increasing pregnancy rates.

Genetic engineering techniques, such as genome editing, have also been recently implemented in pioneering functional studies using human embryos. Gene ablation via the CRISPR/Cas9 system was used to investigate the role of Oct4 in human embryos (Fogarty et al., 2017). In addition, genome engineering was successfully applied to correct for heterozygous mutation of the MYBPC3 gene, which causes hypertrophic cardiomyopathy and results in heart failure (Ma et al., 2017). Although successfully corrected embryos were not transferred to a recipient mother, this provided a proof of principle that mutations escaping natural selection that manifest in adulthood can be eradicated at the current state of technology.

\section{Peri- and early post-implantation embryogenesis}

"Implantation is the most difficult and unpredictable stage", Edwards stated in his ground-breaking article "Test-tube babies", published in Nature in 1981. Implantation is a critical process that mediates the connection of the conceptus to the maternal tissues 
during the early stages of pregnancy. Despite the advances in assisted reproductive technologies, the majority of IVF procedures are not effective mainly as a result of implantation failure. Implantation defects that compromise embryonic development account for $48.6 \%$ of the total pregnancy failures in humanassisted reproduction (Boomsma et al., 2009, Koot et al., 2012). However, the regulatory mechanisms of implantation and the factors governing discontinuation of pregnancy at this critical stage of development are poorly understood.

\section{Steps and maternal control of implantation}

Implantation is initiated at embryonic day four and a half (E4.5) in mice and between E6-E8 in humans (Fig. 1A,B). Once it reaches the uterus, the mature blastocyst that consists of three lineages TE, EPI and PE (hypoblast in human) hatches out of its glycoprotein envelope (zona pellucida). Only embryos that successfully remove their zona pellucida can initiate implantation; therefore, hatching efficiency may act as a final pre-implantation checkpoint of embryonic fitness. In humanART, assisted hatching by thinning, making a hole in or completely removing the zona was introduced as a means to increase embryo potential for implantation. In the following hours immediately after hatching, implantation is initiated, and the embryo invades the uterine wall (Hammadeh et al., 2010).

The implantation process can be subdivided into three steps - apposition, attachment and penetration - and these steps can take place only in a limited period of time known as the implantation widow. This is a restricted period of uterine receptivity, defined by the effects of the maternal hormones ovarian estrogen and progesterone. During apposition, the luminal space of the uterus shrinks to position the floating embryo nearby the luminal epithelium (LE). Interdigitation of microvilli on the surface of TE and LE cells mediates the first direct contact between the mother and the embryo, but this is not sufficient for stable attachment. Normally, the uterine surface is covered with an anti-adhesive mucin layer acting as a barrier against pathogens that would block embryo attachment as well (Surveyor et al., 1995). Only during the short period of uterine receptivity (implantation window) is the mucin layer removed from the LE surface under the control of the maternal hormones and actively by the blastocyst. This is a prerequisite for the establishment of intercellular contacts between the TE and LE, enabling stable attachment of the embryo to the uterine wall (Basak et al., 2002). In mice, the TE induces local apoptosis of the LE, which enables the embryo to breach the underlying basement membrane (BM) and invade the endometrial stroma (Joswig et al., 2003). The human TE invades between the LE cells and, similarly to in mice, penetrates the BM and then invades the underlying stroma. In turn, the stromal cells rapidly proliferate and transform into polyploid decidual cells, which support the development of the conceptus by enabling nutrients, gases and waste exchange, control the depth of TE invasion and ensure fetomaternal immune tolerance (Nancy et al., 2012). The decidualized stroma can also reject implanting embryos, but the mechanisms behind this process are poorly understood. It was recently shown that developmentally compromised human embryos trigger an endoplasmic stress response in decidual cells, whereas developmentally competent embryos induce gene expression of implantation-related factors (Brosens et al., 2014). This suggests the existence of positive and negative selection feedback mechanisms that can discriminate between healthy and developmentally impaired embryos, triggering a specific response for keeping or rejecting the early conceptus.

\section{The inflammation paradox}

The implanting blastocysts of all Eutherian mammals, including of mice and humans, are highly invasive, as they actively penetrate the maternal tissues. Therefore, to maintain pregnancy, the adaptive immune system of the mother has to tolerate the developing embryo. Throughout the gestation period, signs of inflammation have been found at the time of implantation and birth (parturition) that are generally absent during the middle phase of pregnancy (Mor et al., 2011). The inflammation response during implantation is in accord with the active invasion and remodelling of the maternal tissues by the embryo. The "inflammation paradox", then, refers to how immune tolerance is governed to prevent the instant destruction of the embryo while, at the same time, an inflammation response is present at the implantation site. A solution was recently suggested, hypothesising that the process of implantation originated from an inflammatory reaction to embryo attachment in ancestral therian mammals. Implantation, as we know it, evolved as a modified inflammation response by suppressing effects that are harmful for the embryo (e.g. recruitment of effector immune cells, such as neutrophils) and maintaining beneficial inflammatory features, such as an increase in vascular permeability, angiogenesis and the recruitment of regulatory immune cells (e.g. NK cells and macrophages) (Chavan et al., 2017, Griffith et al., 2017). This new concept can explain why anti-inflammatory drugs such as ibuprofen can decrease the frequency of implantation $(\mathrm{Li}$, 2003), whereas surgically scratching the surface of the uterus and therefore promoting an inflammatory response results in increased implantation rates (Gibreel et al., 2015).

\section{Embryonic development during peri- and early post-implan- tation stages}

Before implantation the general architecture of mouse and human blastocysts is very similar despite the differences in the timing of development and the cell numbers that build each of the three lineages (TE, EPI and PE/hypoblast). The interspecies differences become much more distinct as the blastocysts initiate implantation and transform into the early post-implantation conceptus (Fig. 1A,B).

In mice, the mural TE of the E4.5 blastocyst mediates the first direct contact between the embryo and the uterus and differentiates into invasive, polyploid, primary trophoblast giant cells (TGCs) that penetrate into the stroma. During mouse embryogenesis, TGCs are the first terminally differentiated cells that emerge. In contrast to the TGCs, the polar TE maintains its stemness, rapidly proliferates and forms the extraembryonic ectoderm (ExE) that later contributes to the ectoplacental cone (EPC) and ultimately forms all tissues of the embryonic portion of the placenta (reviewed in Bedzhov et al., 2014a, Latos and Hemberger, 2016). In humans, the E6-E7 blastocyst attaches to the LE with its polar TE region, i.e., blastocyst orientation at the implantation site is inverted at $180^{\circ}$ in comparison to the mouse embryo. At the contact site with the uterine epithelium, the polar TE extensively proliferates to give rise to syncytiotrophoblast cells that fuse with each other, forming a syncytium (shared cytoplasm with multiple nuclei). The syncytiotrophoblast invades between 
the LE cells and penetrates into the uterine stroma (E7-E8). TE cells that directly surround the ICM and the blastocoel cavity remain mononucleated, forming the cytotrophoblast that serves as a trophectodermal stem cell pool, similar to the ExE in mice (Okae et al., 2018).

At late blastocyst stage, the mouse EPI is a small, unorganized (apolar) clump of pluripotent cells that is surrounded by a BM, an extracellular matrix layer of laminins and collagens formed by the PE and TE cells. During the peri-implantation stages, between E4.5 and E5.5, polarization cues from the BM trigger epithelialization of the EPI via integrin receptors. As a result, the EPI transforms from a coherent ball of cells into a rosette-like structure, where a central lumen emerges and expands. At E5.5, both the EPI and ExE compartments are essentially cup-shaped epithelia enclosing a common proamniotic cavity that spans in the middle of the egg cylinder (Bedzhov and Zernicka-Goetz, 2014, Bedzhov and Zernicka-Goetz, 2015). In contrast to in mice, the human EPI gives rise to an additional extraembryonic tissue, the amniotic epithelial cells. These cells are specified from EPI cells on the side of the polar cytotrophoblast, whereas EPI cells positioned next to the hypoblast remain pluripotent and form the embryonic disc (E8-E9) (reviewed in Boroviak and Nichols, 2017).

The PE of the mouse blastocyst gives rise to the parietal and visceral endoderm. The parietal endoderm cells delaminate from the PE and migrate over the blastocoel surface of the mural TE. A common BM is established between the parietal endoderm and mural TE layers, forming the so-called Reichert's membrane. The visceral endoderm directly descends from the PE and engulfs both the EPI and ExE compartments of the emerging E5.0 - E5.5 egg cylinder. At the distal tip of the E5.5 embryo, a specialized subpopulation of visceral endoderm cells is established, the distal visceral endoderm. Between E5.5 and E6.5, these cells migrate proximally, on one side of the egg cylinder, and provide signals that specify the anterior identity of the underlying EPI (reviewed in Stower and Srinivas, 2018). At the opposite posterior side of the EPI, gastrulation is initiated at E6.5, resulting in the establishment of the three germ layers (ectoderm, endoderm and mesoderm) that give rise to all somatic lineages, as well as the extraembryonic mesoderm (ExM) that contributes to several supportive tissues, such as the chorion, amnion and yolk sac. In humans, similar to parietal endoderm delamination, cells of the hypoblast migrate over the blastocoel surface of the cytotrophoblast to form the Heuser's membrane at E9. In contrast to in mice, where the ExM is specified from the EPI during gastrulation, the human ExM is derived earlier, from the hypoblast. At E10-E11 the ExM cells invade between the cytotrophoblast and the Heuser's membrane, and later at E12-E13 an ExM lumen (chorionic cavity) is formed. Gastrulation is initiated around E15-E16, as EPI cells ingress through the primitive streak, displacing hypoblast cells to from the definitive endoderm and subsequently migrating between the EPI and endoderm layers to form the mesoderm (reviewed in Rossant and Tam, 2017, Tang et al., 2016).

\section{Culture of mouse embryos beyond blastocyst stage}

In mice, TGC invasion into the uterine stroma triggers the transformation of the stromal cells into decidua, which in turn completely engulfs and conceals the implanting embryo. Within $24 \mathrm{~h}$, between E4.5 and E5.5, the mouse embryo gets completely restructured from a blastocyst into an emerging egg cylinder. These fundamental changes in the shape of the embryo coincide with a burst of cell proliferation as well as transcriptional, epigenetic, metabolic and signalling reorganization in both embryonic and extraembryonic tissues. However, it is still unclear how the developmental process changes gears to shift from pre- to post-implantation embryogenesis. Therefore, determining the embryo culture environment that supports development beyond blastocyst stage is instrumental for providing direct embryo access to study this process ex utero.

The first reports of extended culture of mouse embryos date back to the 1960s and 70s (Fig. 2). In 1964, Bryson placed 2-, 8- and 16-cell stage embryos in diffusion chambers located inside the peritoneal cavity of host male and female mice. The peritoneal fluid displaced the initial medium (1:1 mix of calf serum and $0.9 \%$ $\mathrm{NaCl}$ ) and allowed embryos to develop to blastocyst stage, hatch out of zona pellucida and form an outgrowth on the surface of the $0.45-\mu \mathrm{m}$ pore filter (Millipore) of the chamber. The blastocyst outgrowth consisted of migrating TGCs and ICM that on rare occasions appeared to proliferate and adopt a structure resembling an early egg cylinder (Bryson, 1964). Although the embryos were cultured outside of the uterus, this technique required surgical placement of the diffusion chambers inside the peritoneal cavity. To a certain extent, this approach resembles later, so-called exo utero techniques, where embryos are surgically placed outside the uterus, growing suspended within the mother's abdominal cavity, but still connected to the uterus via the placenta (Muneoka et al., 1986).

To overcome the requirement of a live host, 2- and 4-cell stage embryos were cultured completely in vitro on a feeder cell layer of irradiated HeLa cells in media supplemented with calf or human serum, ATP and glucose. These early cleavage embryos successfully developed to blastocyst stage, attached to the substrate and formed outgrowths with similar appearance as the ones grown on the Millipore filters inside the diffusion chambers (Wolstenholme

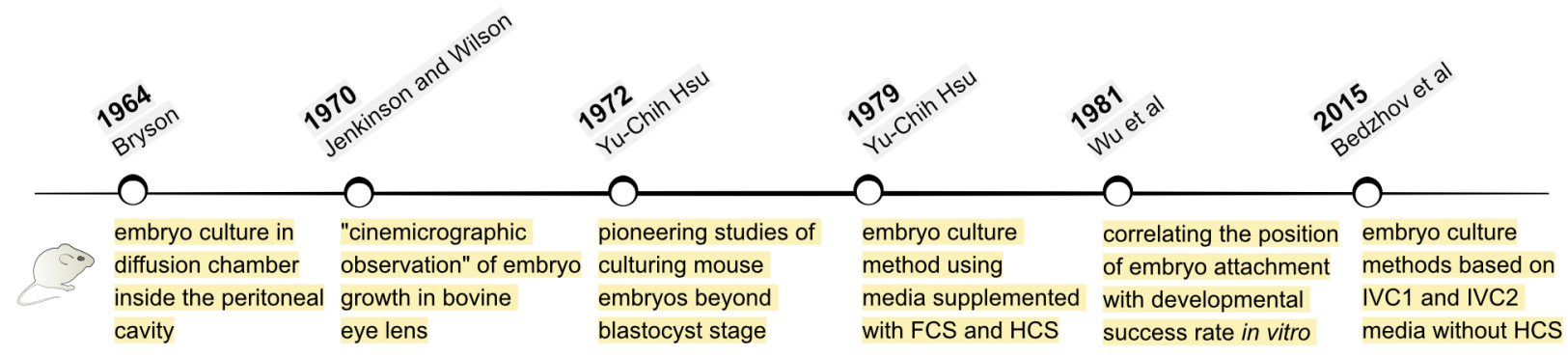

Fig. 2. Selected milestones in the establishment of mouse embryo culture methods supporting development beyond blastocyst stage in vitro. 
A

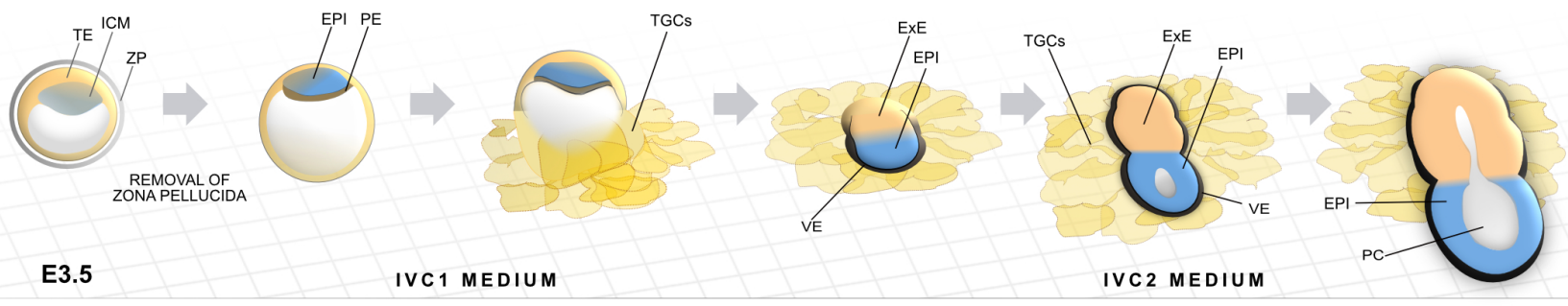

B

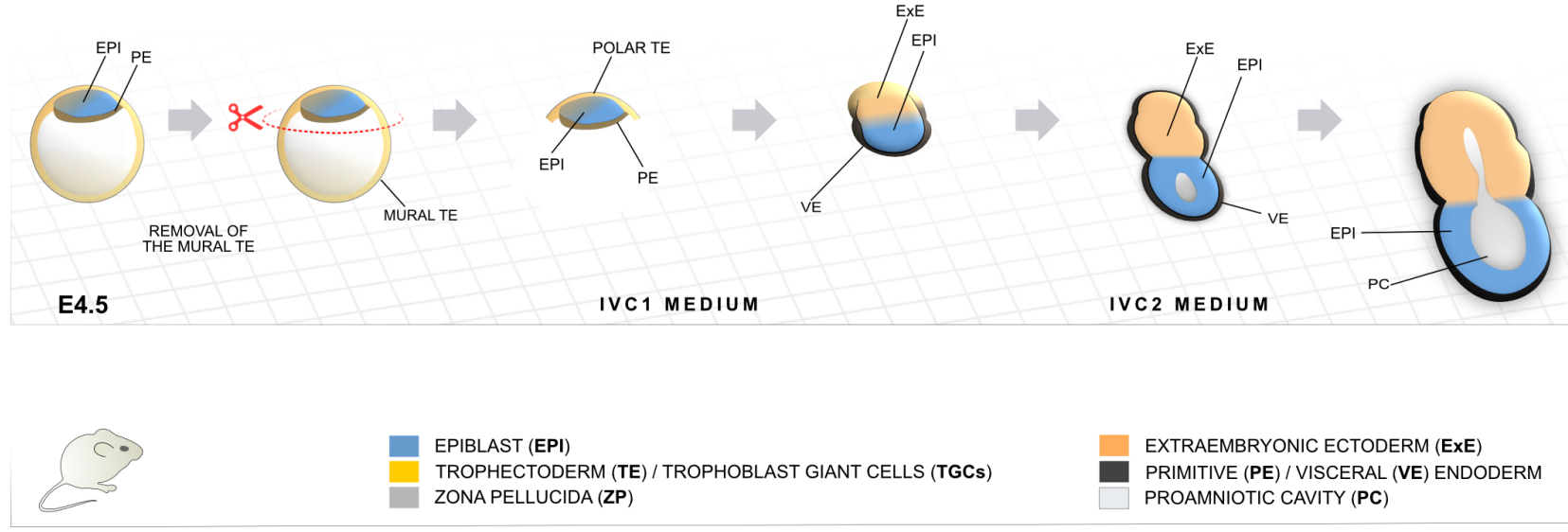

Fig. 3. Mouse embryo culture methods based on in vitro culture $\mathbf{1}$ (IVC1) and IVC2 media. (A) Embryo culture starting from E3.5 blastocyst and subsequent formation of an egg cylinder in vitro. (B) Culture of E4.5 embryos to early egg cylinder stage after dissection of the mural trophectoderm (TE). Based on (Bedzhov et al., 2014b).

and O'Connor, 1965). Later, in 1970, Jenkinson and Wilson injected blastocysts into small pieces of a bovine eye lens to immobilize and keep a constant orientation of the developing embryo, allowing "cinemicrographic observations". The E3.5 blastocysts were cultured for up to $48 \mathrm{~h}$ and, in some cases, formed structures that resemble the $\mathrm{E} 4.75$ stage in vivo or showed disorganized growth (Jenkinson and Wilson, 1970).

After that, in a series of pioneering studies, Yu-Chih Hsu established culture conditions that enabled E3.5 blastocysts to reach the egg cylinder stage in vitro and, although with low efficiency, a few embryos even developed to the early somite stage. Initially, embryos were grown on plastic tissue culture plates coated with rat tail collagen (Hsu, 1972, Hsu, 1973), but later the collagen coating was found to be dispensable (Hsu, 1979). Fine-tuning of the culture medium was a key factor for successful embryonic development in vitro. The first studies were performed using Eagle's minimum essential medium (MEM) supplemented with $10 \%$ calf serum (CS) or $10 \%$ foetal calf serum (FCS) (Hsu, 1972). Later the basal medium was changed from MEM to CMRL-1066 with added sodium pyruvate and glutamine (Gonda and Hsu, 1980, Hsu, 1979). A crucial enhancement to the embryo culture protocol was when human cord serum (HCS) was added. The first days of culture were still performed using CS- or FCS-supplemented medium, which was sufficient to trigger embryo growth and attachment to the substrate, but after that, switching the media from being supplemented with calf sera to human sera was found to be essential for further embryo development in vitro (Gonda and
Hsu, 1980, Hsu, 1979). Using a similar culture protocol, it was determined that blastocysts can attach to the tissue culture plastic at any position of the TE in respect to the ICM. However, embryos that attached to the substrate with their polar TE region tended to develop further with higher success rates (Wu et al., 1981). In combination with time-lapse microscopy, the last reported study using CMRL-1066 medium supplemented with FCS for the first 2 days of culture followed by a switch to HCS-containing medium was able to live-capture the dynamics of anterior visceral endoderm formation in vitro (Morris et al., 2012a).

\section{Establishment of a synthetic medium to bypass the require- ment of human cord serum}

A major obstacle for the broader experimental application of periimplantation embryo culture methods is the requirement of HCS. The serum is derived from the umbilical cord blood of a human placenta immediately after the placenta is released following birth. Collecting HCS requires legal permission to work with human tissue material, informed patient consent and direct access to a maternity clinic. Even if all this is in place, our hands-on experience with HCS has indicated strong batch-to-batch variation in sera derived from different patients that could lead to inconsistent culture conditions. Therefore, a synthetic medium (IVC2) was established to replace HCS-supplemented medium, ensuring at the same time a constant composition of ingredients (Bedzhov et al., 2014b, Bedzhov and Zernicka-Goetz, 2014). Any use of morphogens and pharmacological inhibitors in the medium was deliberately omitted, as it was 
postulated that the developing embryo is a self-organizing entity, and the signalling cues that drive differentiation and patterning are embryo-autonomous (Bedzhov et al., 2015, Bedzhov et al., 2014b). This is supported by the fact that earlier stages (from zygote to blastocyst) can develop in chemically defined medium (KSOM) without a maternal input, successfully undergoing major developmental events (e.g. first and second cell fate decisions). Thus, if proper culture conditions are provided, embryonic development in vitro can extend beyond the peri-implantation stages, independently of the mother. Hypothesizing that the maternal environment mainly provides nutrients, pregnancy-related hormones and mediates gas and waste exchange, advanced-DMEM/F12 was implemented as a more nutritious basal medium instead of MEM or CMRL-1066. The medium was further supplemented with ITS-X (insulin-transferrinselenium-ethanolamine) to generally reduce the serum requirement, $\mathrm{KSR}$ (knock-out serum replacement), as well as pregnancy-related steroid hormones (progesterone and $\beta$-estradiol), L-glutamine and antibiotics (penicillin and streptomycin). As the embryo culture method was designed to be compatible with confocal microscopy, $\mathrm{N}$-acetyl-L-cysteine was incorporated to reduce oxidative stress caused by reactive oxygen species generated during laser illumination (Bedzhov et al., 2014b, Bedzhov and Zernicka-Goetz, 2014).

Depending on the starting stage of development, either E3.5 or E4.5, two protocols for in vitro culture were established (Fig. 3A,B). Early blastocysts (E3.5) are still encapsulated within zona pellucida, and this was removed via brief exposure to Tyrode's solution (Fig. $3 \mathrm{~A})$, as embryos that fail to hatch naturally do not develop further, either in vivo or in vitro. As a substrate, tissue culture optical-grade plastic (ibidi) was utilized to allow embryo attachment and simultaneous high-resolution imaging. For the first two days, the embryos were cultured in IVC1 medium with the same composition as IVC2 but contained stem cell-grade FCS instead of KSR. The serum component is required to trigger the initial blastocyst growth and TE differentiation to TGCs, which mediate the attachment to the plate. At day 3, the medium was exchanged to IVC2 to support further growth of the emerging egg cylinder that takes around 5 days in total, with average efficiency rates of 20 - 25\% (Bedzhov et al., 2014b, Bedzhov and Zernicka-Goetz, 2014).

Although the mural TE is required for the embryo to invade the uterine stroma in vivo, this compartment is dispensable for embryo development on a plastic plate. Therefore, after isolating E4.5 embryos that were already hatched, the mural TE was cut away completely, leaving only a clump of ICM and polar TE cells (Fig. 3B). The small clumps were cultured in IVC1, which was changed to IVC2 on the second day. As a result, the embryo development to egg cylinder stage was faster (3 days) and substantially more efficient (40 - $45 \%$ ) (Bedzhov et al., 2014b). Nevertheless, the overall success rate of egg cylinder formation in vitro never reached $100 \%$, clearly indicating that there is space to further optimize the method. We further discuss the potential influence of the culture conditions on the developmental process and the adaption of the embryo to the external environment in the last chapter.

\section{Culture of post-implantation mouse embryos explanted from the uterus}

Egg cylinders or later organogenesis stages that are already formed in vivo can be used in culture experiments focused on analysing post-implantation developmental processes. Growing post-implantation embryos in vitro allows for direct observations and manipulations of the developing embryo for a limited period of time. Prior to culture, the embryos have to be dissected out of the uterine tissues and, depending on the stage, extraembryonic tissues such as the Reichert's membrane (early post-implantation) or the yolk sac (late-post-implantation) have to be cut open. The protocols for culturing mouse embryos were largely adopted from methods used for growing rat embryos in vitro. Therefore, media supplemented with rat serum (RS) (Piliszek et al., 2011) or a combination of RS and HCS are most commonly used for post-implantation mouse embryo culture (Tam, 1998). Although not clearly defined, the properties of the serum are of key importance for successful in vitro development. For example, E8.5 rat embryos grown in homologous RS developed normal (single) or abnormal (double) hearts depending on the way the RS was technically prepared: RS derived from blood after clotting resulted in double heart formation, whereas embryos grown in RS prepared from blood before clotting formed single hearts (Steele and New, 1974). Thus, even seemingly minor differences in the serum can influence the experimental outcome and reproducibility. Therefore, we routinely culture post-implantation embryos in synthetic IVC2 medium, as, in contrast to the serum-containing media, IVC2 lacks morphogens that can influence the developmental programme of certain tissues and avoids serum batch variability (Bedzhov et al., 2015, Govindasamy and Bedzhov, in press).

Post-implantation embryos can be cultured for several days in vitro, although a time frame of two and a half days is recommended, as extensive periods of culture inevitably result in growth retardation and developmental malformations (Rivera-Pérez et al., 2010). Depending on the developmental stage, the oxygen and,

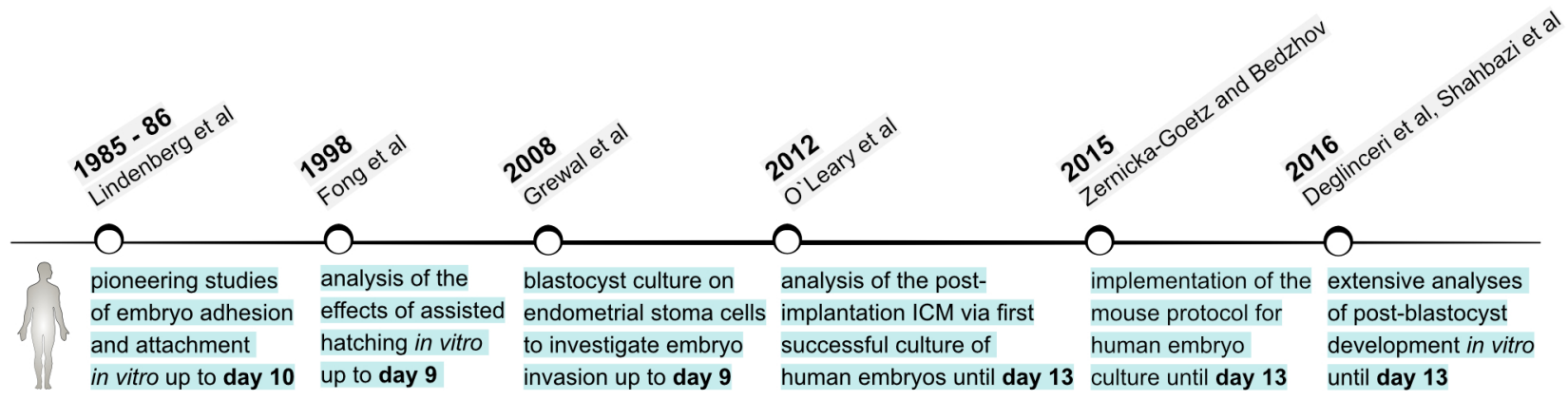

Fig. 4. Selected milestones in the establishment of human embryo culture methods supporting development beyond blastocyst stage in vitro. 
respectively, the nitrogen content of the embryo culture atmosphere has to be adjusted as well, starting from $5 \% \mathrm{O}_{2} / 90 \% \mathrm{~N}_{2}$ (E5.5-E7.5), $20 \% \mathrm{O}_{2} / 75 \% \mathrm{~N}_{2}$ (E8.5-E9.5), 40\% O $/ 55 \% \mathrm{~N}_{2}$ (E9.5-E10.5) and $95 \% \mathrm{O}_{2}$ (E10.5-E11.5), whereas $\mathrm{CO}_{2}$ is kept constant at $5 \%$. The in vitro development of the later stages is greatly enhanced when embryos are grown in rolling culture bottles, enabling constant gassing of the medium (Cockroft, 1990).

\section{Culture of human embryos beyond blastocyst stage}

Compared to our understanding of the mouse as a model system, we know much less about the process of human implantation, as well as the molecular and cellular mechanisms governing the peri- and early post-implantation development of the human embryo. Most of our knowledge about human embryogenesis during the first weeks of post-implantation development comes from few histological analyses of implanted embryos (O'Rahilly etal., 1987). These stages of human development are inaccessible for experimentation due to obvious ethical reasons, as well as because of technical and legal restrictions. Thus, extended culture of human blastocysts throughout and beyond the implantation stages in vitro is instrumental to broaden our understanding of early human embryogenesis.

The first reports of culturing human embryos beyond blastocyst stage were the pioneering studies of Svend Lindendberg that date back to the late 1980s and 90s (Fig. 4). The main focus of his research was to understand human implantation by recapitulating in vitro the main steps in this process: blastocyst apposition, adhesion and attachment. After performing IVF of donor oocytes, Lindendberg placed embryos that developed to blastocyst stage (day 6) on a monolayer of human uterine epithelial cells. One out of three blastocysts successfully hatched and adhered to the epithelial layer at day 9-10. This experiment showed, for the first time, that a human embryo can survive and develop in vitro longer than the pre-implantation period. Although, adhesion was successful, there was no formation of an outgrowth and stable attachment (Lindenberg et al., 1985). This was achieved in subsequent experiments, where blastocysts were cultured again on a layer of human uterine epithelial cells, but in the presence of media supplemented with $15 \%$ serum from the patient. These culture conditions enabled faster adhesion to the epithelial monolayer (days 7-8), which was initiated by the polar TE region, similar to the implantation process in vivo. The polar TE gave rise to a cytotrophoblast that displaced the epithelial cells, forming stably attached blastocyst outgrowth (days 8-10) (Lindenberg, 1991, Lindenberg et al., 1986).

Later, ultrastructural analyses of the in vitro interactions between human blastocysts and cultured endometrial cells indicated that putative syncytiotrophoblast cells of the blastocyst outgrowth breached the endometrial epithelium by intrusive penetration (between the epithelial cells) (Bentin-Ley et al., 2000). The subsequent events of the invasion into the uterine stroma were modelled in vitro by Helen Mardon's group, using endometrial stromal cells as a substrate for culturing human blastocysts (up to day 9 post-insemination). In this study, for the first time the process of embryo attachment and invasion of the stromal cell monolayer was captured by time-lapse microscopy (Carver, 2003). In a following report, the same group investigated the role of the Rho GTP-ases Rac1 and Rho in this process. Rac1 knockdown in human endometrial stroma cells inhibited embryo invasion, whereas blocking RhoA activity promoted trophoblast penetration of the stromal cell layer. In accord with these observations, increased motility of the stromal cells at the site of blastocyst attachment in vitro was associated with elevated Rac1 activity and decreased expression of the Rac1 negative regulator RacGAP1. This suggests that the embryo can modulate activity and expression levels of key regulators of cell motility and migration in the endometrial stroma, thus facilitating a local, embryo-induced endometrial response that may govern implantation of the human embryo (Grewal et al., 2008).

\section{In vitro blastocyst attachment as an assisted reproductive technology assay with potential clinical relevance}

Implantation failure is the foremost cause of human infertility following IVF, but the inaccessibility of the implantation site limits studies addressing the clinical aspects of this process (Boomsma et al., 2009, Koot et al., 2012). Thus, extended culture of human blastocysts throughout the implantation stages can help to elucidate whether certain ARTs can improve pregnancy rates. For example, "in vitro implantation" of human blastocysts was used as an assay to understand and predict the effects of zona pellucida removal on the success rate of clinical pregnancy. Hatched blastocysts (day 5) were cultured for 3-4 days in MEM medium supplemented with human LIF (leukaemia inhibitory factor). Several types of irradiated cell monolayers were used for co-culturing the blastocysts (human endometrial cells [mixed glands and stromal cells], human tubal epithelial cells, Vero cells, human foetal fibroblasts, murine foetal fibroblasts and mouse STO fibroblasts). A high percentage (92\%) of the zona-free blastocysts attached in vitro, with no significant variations of the attachment rates between the different feeder cell types. In parallel, artificially hatched blastocysts (day 5) were transferred to 19 patients, resulting in a $53 \%$ clinical pregnancy rate per transfer. Notably, $40 \%$ of the pregnancies were multiple, and two of them were triplets. Taken together, this indicated that assisted hatching provides a significant enhancement of ART and, at the same time, defines a requirement for reducing the number of transferred embryos to minimize the chance of a multiple pregnancy. The authors also suggested that spare embryos can be cryopreserved as a backup pool of blastocysts for subsequent transfers, if necessary (Fong et al., 1998).

Determining the efficiency of in vitro attachment of human blastocysts was also beneficial for more closely assessing the effects of drugs used for contraception, such as UPA (ulipristal acetate). UPA is progesterone receptor modulator that is used for emergency contraception, known also as the "morning after pill". Administration of UPA delays or completely inhibits follicular development and ovulation, but histological analysis of endometrial tissues suggested that UPA may also affect the process of implantation (Berger et al., 2015, Chabbert-Buffet et al., 2005). As the effects of UPA on the human embryo-maternal interactions cannot be studied in vivo, the drug or vehicle alone were added to the culture medium of hatched blastocysts that were grown in vitro for 5 days. The authors concluded that there was no significant difference in the formation of blastocyst outgrowths and attachment rates between the UPA and control groups, suggesting that UPA used in the prescribed dose for contraception does not affect embryo implantation capacity (Berger et al., 2015).

\section{Towards the $14^{\text {th }}$ day margin of human embryo culture}

The use of human embryos for research is strictly forbidden in many countries, and in others the time of human embryo culture 
is limited to 14 days after fertilization. The so-called " $14^{\text {th }}$ day rule" restricts human embryo experiments to a period of time that extends up to but not beyond the initiation of gastrulation, which in vivo is marked by primitive streak formation at day 15 (Appleby and Bredenoord, 2018). Reaching this time limit in vitro is not always an experimental necessity but depends on the biological question being addressed. Embryo culture until days 9-10 was sufficient to investigate blastocyst attachment and invasion of endothelial cells (Carver, 2003, Grewal et al., 2008, Lindenberg, 1991, Lindenberg et al., 1986), but other studies may require reaching as close as possible to the $14^{\text {th }}$ day while at the same time maintaining the development of both embryonic and extraembryonic lineages in near physiological conditions in order to achieve faithful recapitulation of human embryogenesis in vitro. The first studies by Lindendberg have already indicated that this is a major experimental challenge. Lindendberg's culture conditions (medium supplemented with 15\% human serum) maintained the development of the trophoblast lineage, allowing adhesion and subsequent attachment of the human blastocyst, but the ICM showed signs of degeneration (Lindenberg et al., 1986). The first report that aimed specifically to maintain the ICM used fallopian tube epithelial cells as a feeder layer for culturing human blastocysts in the presence of Chang's medium supplemented with $10 \%$ human serum and human LIF.
Two days after hatching, the embryos attached and formed an outgrowth that maintained a healthy ICM "lump" up to day 11 post-insemination (Bongso et al., 1994). In a more recent study, day 5 human blastocysts were co-cultured for an additional $72 \mathrm{~h}$ (day 8 post-fertilization) on decidualized human endometrium in DMEM/F-12 complete medium. This extended blastocyst culture was required for comparison of day 5 blastocyst with day 8 blastocyst outgrowths in order to investigate the process of X-chromosome inactivation at the time of implantation. Notably, day 8 blastocyst outgrowths maintained the ICM lineages and showed proper segregation of Oct4-positive EPI and Gata4-positive hypoblast cells (Wu et al., 2012).

Conventional human embryonic stem cells (hESC) are derived from blastocyst stage embryos and are typically maintained in medium supplemented with bFGF (basic fibroblast growth factor) in the presence of mitotically inactivated mouse embryonic fibroblasts (MEFs) (Chen et al., 2009). Are hESC culture conditions suitable for growing human embryos in vitro? Usually, during the first steps of hESC derivation, the ICM is isolated by destroying the TE via immunosurgery or laser ablation. Moreover, in comparison to intact embryos, one study showed that ICM isolation significantly increased the rate of hESC derivation, whereas maintaining the TE proved to be counterproductive (Chen et al., 2009). Neverthe-
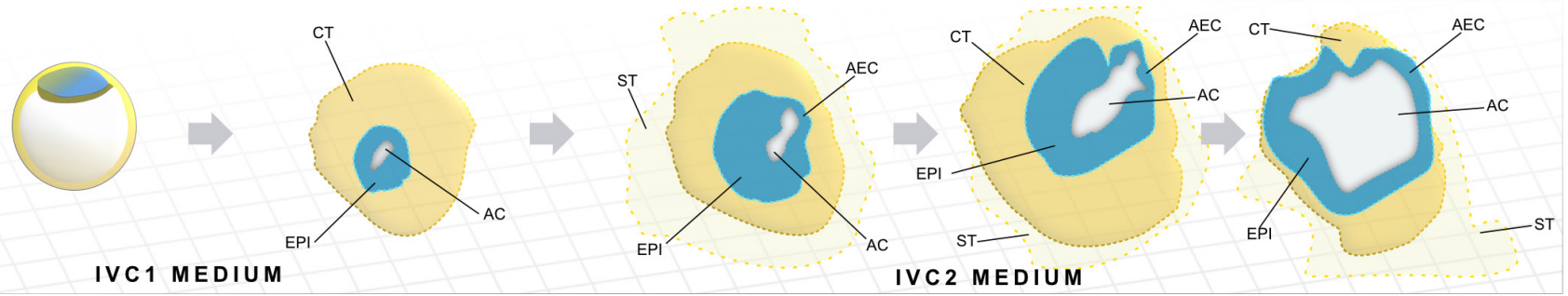

DAY 6

DAY 9

DAY 10

IVC2 MEDIUM
DAY 11

DAY 13
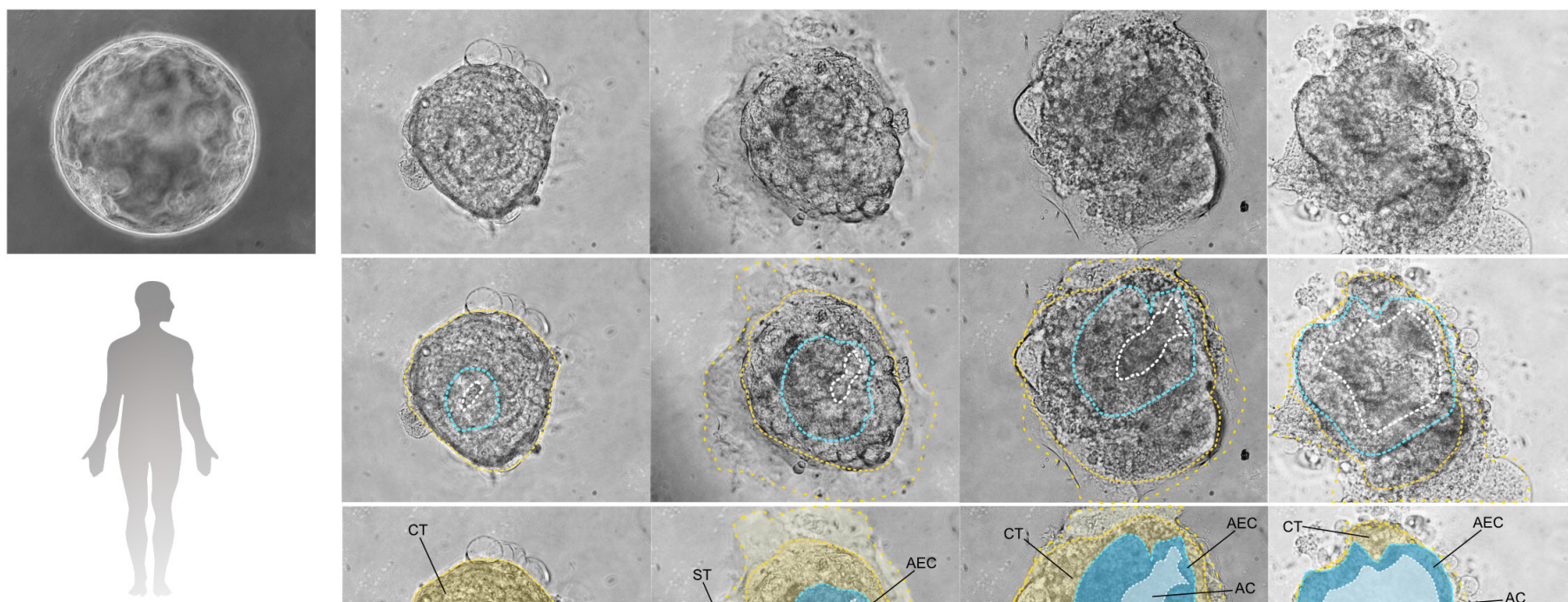

PUTATIVE TISSUES

EPIBLAST (EPI)

CYTOTROPHOBLAST(CT)

SYNCYTIOTROPHOBLAST (ST) AMNIOTIC CAVITY (AC)
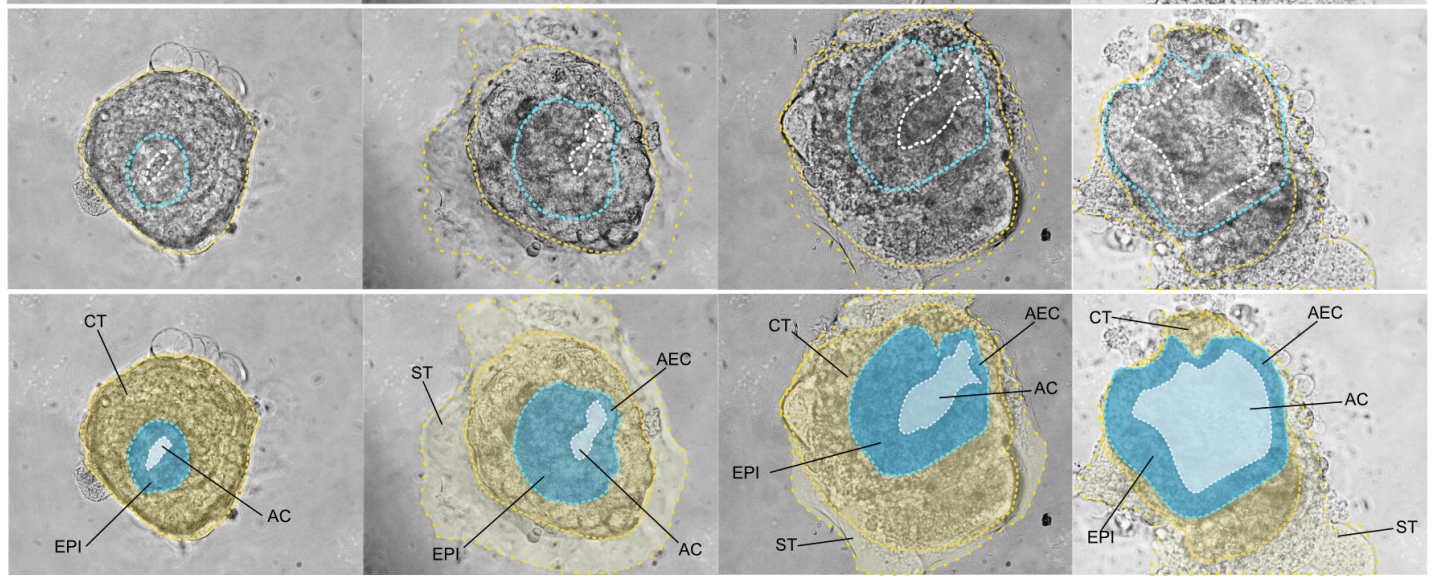

Fig. 5. Human embryo culture method based on in vitro culture 1 (IVC1) and IVC2 media supporting in vitro embryogenesis until day 13 (according to Zernicka-Goetz and Bedzhov, 2015, GB2517194A, https://patents.google.com/patent/GB2517194A/). 
less, intact blastocysts cultured for 5 days in hESC medium on MEFs were able to attach, forming an outgrowth, even though the outgrowths consisted mainly of trophoblast cells and generally lacked Oct4-positive EPI (Niakan and Eggan, 2013). However, Oct4-positive EPI cells were clearly identified when a larger number of human blastocysts with good-quality ICM were used for generating outgrowths in conventional hESC medium (O'Leary et al., 2012, O'Leary et al., 2013b). After fertilization (day 0), human embryos were cultured until blastocyst stage (day 6) in Cook preimplantation media. At day 6, zona pellucida was removed and the blastocysts were plated on MEFs and cultured for an additional 7 days in the presence of hESC medium (O'Leary et al., 2013b). After attachment, the ICM formed a post-implantation EPI-like structure termed post-ICM intermediate (PICMI). The PICMI cells were Oct4-positive, and those cells in female embryos had undergone X-chromosome inactivation. The outer layer, adjacent to the PICMI, contained Gata6-positive / Oct4-negative cells resembling the hypoblast. Moreover, the PICMI were able to give rise to hESC lines, further confirming the EPI identity of these structures. The authors concluded that PICMI is formed as a result of "progressive and defined ICM organization in vitro" and corresponds to the human EPI disc in vivo (O'Leary et al., 2012). This remarkable study not only demonstrates that hESC have a post-implantation EPI origin, but to our knowledge this is the first report of a successful culture of human embryos until day 13 post-fertilization.

\section{Implementing mouse embryo culture conditions to successfully grow human embryos in vitro}

As further development of mouse blastocysts was achieved in vitro using a combination of FCS-containing (IVC1) and serum-free (IVC2) media (Bedzhov etal., 2014b, Bedzhov and Zernicka-Goetz, 2014), it is feasible that similar culture conditions can also support human post-implantation embryogenesis in vitro (Fig. 5). In a pilot study, with the help of Kathy Niakan and Agnieszka Jedrusik, zonafree blastocysts were plated on uncoated, optical-grade plastic plates (Ibidi). From day 6 to day 9 the embryos were cultured in IVC1 medium that triggered TE differentiation and embryo attachment to the substrate. Once stable attachment was achieved (day 9), IVC1 was exchanged with an intermediate IVC-medium supplemented with 10\% FCS and $10 \%$ KSR. From day 10 until day 13, the embryos were cultured in the presence of synthetic IVC2 medium. At this time point, embryo culture was stopped, as of the $14^{\text {th }}$ day limit. From the time of attachment until the end of the culture period, development of different tissues became clearly visible - the trophoblast rapidly proliferated and started spreading out, and, at the same time, a putative amniotic cavity emerged and an embryonic disc-like structure was established. Thus, by adapting the mouse embryo culture protocol, human embryos were successfully cultured beyond blastocyst stage reaching the $14^{\text {th }}$ day border (Zernicka-Goetz and Bedzhov, 2015). The results of this pilot study were included in a patent application (GB2517194A) that contains all the details of the embryo culture protocol and is available as a resource online (https://patents.google.com/patent/ GB2517194A/)

Later the same year, the mouse embryo culture conditions (Bedzhov et al., 2014b, Bedzhov and Zernicka-Goetz, 2014) were probed for culturing human monozygotic twin embryos in a study published by Dusko llic's group. In order to investigate the embryo quality of artificially generated monozygotic twins, 2-5 or
6-10 cell stage human embryos were split in half and cultured in vitro. Although the monozygotic twin embryos formed blastocysts, the ICMs were poorly developed or undistinguishable, and none of them was capable of giving rise to hESC lines. Not surprisingly, twin embryos also failed to grow after day 6 using the IVC1 / IVC2 mouse embryo culture media (Noli et al., 2015). This suggests that a certain minimum number of ICM cells is required for proper human embryonic development in vitro and most likely in vivo, as well. Similarly, an insufficient number of EPI cells results in developmental failure in mice (Balbach et al., 2010, Morris et al., 2012b).

Recently, two studies successfully implemented the mouse embryo culture protocol (Bedzhov et al., 2014b, Bedzhov and Zernicka-Goetz, 2014) to grow intact human embryos until day 13 in vitro (Deglincerti et al., 2016, Shahbazi et al., 2016). Snapshot analysis of fixed embryos from day 6 to day 13 of culture, using molecular markers to characterize the embryonic and extraembryonic lineages, revealed that key features of normal embryogenesis were achieved in vitro. This includes EPI/hypoblast lineage segregation, EPI expansion and formation of the embryonic disc, amniotic cavity and yolk sac, as well as trophoblast differentiation (Deglincerti et al., 2016, Shahbazi et al., 2016). These results strongly indicate that the main aspects of human development taking place during the first days after blastocyst stage can be faithfully recapitulated without maternal input, if sufficient culture conditions are provided. Blastocyst outgrowth analysis also suggested the existence of a previously unknown extraembryonic cell population, the yolk sac trophectoderm, which lines the yolk sac cavity (Deglincerti et al., 2016). This further emphasises it is important to conduct experiments not only using model organisms but also with human tissues and embryos for research in order to truly understand the nature of our own development.

\section{Things to consider}

Earth is the ultimate culture system where living matter evolves as a response to the ever-changing environment; species that fail to adapt inevitably face extinction. Similarly, living matter placed in an in vitro culture system have two options, to adapt or to vanish. The in vitro culture systems are artificially generated approximations of an in vivo environment, but so far they have never represented a complete, undistinguishable reproduction of it. Thus, the process of adaptation may take different paths depending on the experimental conditions and the internal state of the living system. The most obvious in vitro deviation in comparison to in vivo embryogenesis is the developmental delay observed by Hsu and Lindenberg in their pioneering experiments with mouse and human blastocysts (Hsu, 1978, Lindenberg et al., 1986); this additional time required for embryo development in vitro was attributed to external environment adaptation (Hsu, 1978). Another striking example of the influence of the culture environment is the seemingly minor technical differences in preparing the serum constituent of the culture medium that result in normal or abnormal (double) heart formation in rat embryos (Steele and New, 1974). Various factors, such as multiple, collective effects of the culture conditions (composition of the medium, oxygen content of the atmosphere, substrate, cell lines used for co-culture etc.) and the specific embryo state (genetic background, embryo quality, removal or maintenance of certain extraembryonic tissues etc), can determine the developmental outcome and the overall culture efficiency. Developmental aberrations that occur in 
vitro may not necessarily have a clear morphological manifestation, such as the double heart in rat embryos, but they might be detectable on metabolic, transcriptional or / and epigenetic levels. Thus, results from individual experiments, such as gene expression profiling, may substantially differ if the culture conditions are not standardized, despite seemingly proper embryo development in vitro. Therefore, embryo culture protocols have to be described and followed in detail to ensure experimental reproducibility. The logic behind establishing new culture conditions, as well as modifying existing methods, should be clearly rationalised to allow future improvements. This will ultimately make the difference between "cooking" and systematically designing methods for embryo culture.

The mouse, as a model system for mammalian development in vitro, benefits from the long-term accumulation of knowledge and understanding about murine in vivo embryogenesis. Fine electron microscopy studies, detailed histology, immunohistochemistry and RNA-in situ analyses of gene expression, next generation sequencing, including single cell RNA-seq and, importantly, finetuned transgenic technology that enables functional studies, are all resources that can be used to compare and interpret experimental results obtained in vitro. Altogether, this can help to address a very important question: Is what we see in vitro real, or is it an artefact caused by the culture environment? In the case of human development beyond blastocyst stage, because of obvious ethical reasons we have no access to implanted embryos, and, with the exception of the few histology studies, our sources of information are very limited. Thus, culture of human blastocyst outgrowths is a double-edged sword. On the one hand, at the current state of technology, this is our best tool to study early post-implantation embryogenesis; on the other hand, every novel finding coming from such in vitro experiments has to be taken with caution, as one has to always keep in mind that the in vitro observations may not match the developmental process in vivo, and our toolbox to check this notion is extremely narrow. Thus, forming general conclusions about human embryogenesis requires independently reproducible experimental results as well as, whenever possible, comparative studies using close, evolutionarily related systems, such as non-human primates.

Implantation failure is the leading cause for early miscarriage following IVF (Boomsma et al., 2009, Koot et al., 2012), and both mouse and human in vitro culture systems hold great promise for helping us understand the mechanisms behind normal implantation and the defects that can disrupt this process. The success of implantation depends on two sides, the blastocyst and the maternal environment, to mutually establish a functional connection. Thus, in order to faithfully model the implantation process in vitro, both the embryo and the maternal tissues have to be part of the culture system. However, the general experimental approach for designing the culture environment has been so far "embryo-centric", i.e. focused on supporting the growth of the embryo, whereas the mother side has been oversimplified using tissue culture plastic. Although the general tissue composition of the uterus is well studied, we know little about the dynamics of the maternal environment as it adjusts to optimally support each step of embryo development. Therefore, establishing a three-dimensional artificial environment that mimics the maternal tissues is a major challenge for the future development of both mouse and human in vitro culture systems.

The establishment and implementation of both pre- and postimplantation embryo culture systems have come a long way, re- sulting in streamlined protocols supporting in vitro embryogenesis from fertilization until blastocyst stage. This has a direct impact on the development and optimization of ARTs, which will translate into higher success rates of pregnancy in human-assisted reproduction. The continuous advances of the embryo culture methods have allowed further ex utero development beyond the blastocyst stage, and this holds great promise for elucidating the hidden mechanisms of implantation. Taken together, the pre- and postimplantation culture approaches might hold the key to understanding life's greatest miracle - the development of a new organism.

\section{Acknowledgements}

This work was supported by the German Research Foundation (DFG) Emmy Noether grant (BE 5800/1-1) to I.B., the Cells in Motion cluster of excellence / International Max Plank Research School (CiM/IMPRS) PhD fellowship of N.G., the DFG research grant (BE-5800/2-1) support of B.D. and the CRC Dynamic cellular interfaces grant (1348/1, B09) support of H.O.O.

\section{References}

AINSWORTH, A.J., FREDRICKSON, J.R. and MORBECK, D.E. (2017). Improved detection of mineral oil toxicity using an extended mouse embryo assay. J. Assisted Reprod. Genet. 34: 391-397.

AJDUK, A., ILOZUE, T., WINDSOR, S., YU, Y., SERES, K.B., BOMPHREY, R.J., TOM, B.D., SWANN, K., THOMAS, A., GRAHAM, C. et al., (2011). Rhythmic actomyosin-driven contractions induced by sperm entry predict mammalian embryo viability. Nat Commun 2: 417.

APPLEBY, J.B. and BREDENOORD, A.L. (2018). Should the 14-day rule for embryo research become the 28-day rule? EMBO Molec. Med.

BALBACH, S.T., ESTEVES, T.C., BRINK, T., GENTILE, L., MCLAUGHLIN, K.J., ADJAYE, J.A. and BOIANI, M. (2010). Governing cell lineage formation in cloned mouse embryos. Dev Biol 343: 71-83.

BASAK, S., DHAR, R. and DAS, C. (2002). Steroids modulate the expression of alpha4 integrin in mouse blastocysts and uterus during implantation. Biol Reprod 66: 1784-1789.

BEDZHOV, I., BIALECKA, M., ZIELINSKA, A., KOSALKA, J., ANTONICA, F., THOMPSON, A.J., FRANZE, K. and ZERNICKA-GOETZ, M. (2015). Development of the anterior-posterior axis is a self-organizing process in the absence of maternal cues in the mouse embryo. Cell Res 25: 1368-1371.

BEDZHOV, I., GRAHAM, S.J., LEUNG, C.Y. and ZERNICKA-GOETZ, M. (2014a) Developmental plasticity, cell fate specification and morphogenesis in the early mouse embryo. Philos Trans $R$ Soc Lond B Biol Sci 369.

BEDZHOV, I., LEUNG, C.Y., BIALECKA, M. and ZERNICKA-GOETZ, M. (2014b). In vitro culture of mouse blastocysts beyond the implantation stages. Nat Protoc 9: 2732-2739.

BEDZHOV, I. and ZERNICKA-GOETZ, M. (2014). Self-organizing properties of mouse pluripotent cells initiate morphogenesis upon implantation. Cell 156: 1032-1044.

BEDZHOV, I. and ZERNICKA-GOETZ, M. (2015). Cell death and morphogenesis during early mouse development: are they interconnected? Bioessays 37:372-378.

BENTIN-LEY, U., HORN, T., SJOGREN, A., SORENSEN, S., FALCK LARSEN, J. and HAMBERGER, L. (2000). Ultrastructure of human blastocyst-endometrial interactions in vitro. Reproduction 120: 337-350.

BERGER, C., BOGGAVARAPU, N.R., MENEZES, J., LALITKUMAR, P.G.L. and GEMZELL-DANIELSSON, K. (2015). Effects of ulipristal acetate on human embryo attachment and endometrial cell gene expression in an in vitro co-culture system. Human Reprod. 30: 800-811

BONGSO, A., FONG, C.-Y., NG, S.-C. and RATNAM, S. (1994). Fertilization and early embryology: Isolation and culture of inner cell mass cells from human blastocysts. Human Reprod. 9: 2110-2117.

BOOMSMA, C.M., KAVELAARS, A., EIJKEMANS, M.J., LENTJES, E.G., FAUSER, B.C., HEIJNEN, C.J. and MACKLON, N.S. (2009). Endometrial secretion analysis identifies a cytokine profile predictive of pregnancy in IVF. Hum Reprod 24: 1427-35.

BOROVIAK, T. and NICHOLS, J. (2017). Primate embryogenesis predicts the hallmarks of human naïve pluripotency. Development 144: 175-186. 
BRAUDE, P., BOLTON, V. and MOORE, S. (1988). Human gene expression first occurs between the four- and eight-cell stages of preimplantation development. Nature 332: 459.

BROSENS, J.J., SALKER, M.S., TEKLENBURG, G., NAUTIYAL, J., SALTER, S., LUCAS, E.S., STEEL, J.H., CHRISTIAN, M., CHAN, Y.-W., BOOMSMA, C.M. et al., (2014). Uterine Selection of Human Embryos at Implantation. Scientific Rep. 4.

BRYSON, D.L. (1964). Development of Mouse Eggs in Diffusion Chambers. Science 144: 1351-1353.

CARVER, J. (2003). An in-vitro model for stromal invasion during implantation of the human blastocyst. Human Reprod. 18: 283-290.

CHABBERT-BUFFET, N., MEDURI, G., BOUCHARD, P. and SPITZ, I.M. (2005). Selective progesterone receptor modulators and progesterone antagonists: mechanisms of action and clinical applications. Human Reprod. Update 11: 293-307.

CHAVAN, A.R., GRIFFITH, O.W. and WAGNER, G.P. (2017). The inflammation paradox in the evolution of mammalian pregnancy: turning a foe into a friend. Curr. Opin. Genet. Dev. 47: 24-32.

CHEN, A.E., EGLI, D., NIAKAN, K., DENG, J., AKUTSU, H., YAMAKI, M., COWAN, C., FITZ-GERALD, C., ZHANG, K., MELTON, D.A. et al., (2009). Optimal Timing of Inner Cell Mass Isolation Increases the Efficiency of Human Embryonic Stem Cell Derivation and Allows Generation of Sibling Cell Lines. Cell Stem Cell 4: 103-106.

COCKROFT, D.L. (1990). Dissection and culture of post implantation embryos. Mammalian Postimplantation Embryos A Practical Approach. Oxford: IRL Press.

DEGLINCERTI, A., CROFT, G.F., PIETILA, L.N., ZERNICKA-GOETZ, M., SIGGIA, E.D. and BRIVANLOU, A.H. (2016). Self-organization of the in vitro attached human embryo. Nature 533: 251-254.

EDWARDS, R.G. (1981). Test-tube babies, 1981. Nature 293: 253-256.

EDWARDS, R.G., STEPTOE, P.C. and PURDY, J.M. (1970). Fertilization and cleavage in vitro of preovulator human oocytes. Nature 227: 1307-1309.

FOGARTY, N.M.E., MCCARTHY, A., SNIJDERS, K.E., POWELL, B.E., KUBIKOVA, N., BLAKELEY, P., LEA, R., ELDER, K., WAMAITHA, S.E., KIM, D. et al., (2017). Genome editing reveals a role for OCT4 in human embryogenesis. Nature 550:67-73.

FONG, C.Y., BONGSO, A., NG, S.C., KUMAR, J., TROUNSON, A. and RATNAM, S. (1998). Blastocyst transfer after enzymatic treatment of the zona pellucida: improving in-vitro fertilization and understanding implantation. Human Reprod. 13: 2926-2932.

GIBREEL, A., EL-ADAWI, N., ELGINDY, E., AL-INANY, H., ALLAKANY, N. and TOURNAYE, H. (2015). Endometrial scratching for women with previous IVF failure undergoing IVF treatment. Gynecol. Endocrinol. 31: 313-316.

GONDA, M.A. and HSU, Y.-C. (1980). Correlative scanning electron, transmission electron, and light microscopic studies of the in vitro development of mouse embryos on a plastic substrate at the implantation stage. J. Embryol. Exp. Morphol 56:23-39.

GOVINDASAMY, N. and BEDZHOV, I. (in press). Isolation and culture of periimplantation and early post-implantation mouse embryos. Methods Mol Biol.

GREWAL, S., CARVER, J.G., RIDLEY, A.J. and MARDON, H.J. (2008). Implantation of the human embryo requires Rac1-dependent endometrial stromal cell migration. Proc. Natl. Acad. Sci. USA 105: 16189-16194.

GRIFFITH, O.W., CHAVAN, A.R., PROTOPAPAS, S., MAZIARZ, J., ROMERO, R. and WAGNER, G.P. (2017). Embryo implantation evolved from an ancestral inflammatory attachment reaction. Proc. Natl. Acad. Sci. USA 114: E6566-E6575.

HAMATANI, T., CARTER, M.G., SHAROV, A.A. and KO, M.S. (2004). Dynamics of global gene expression changes during mouse preimplantation development. Dev Cell 6: 117-131.

HAMMADEH, M.E., FISCHER-HAMMADEH, C. and ALI, K.R. (2010). Assisted hatching in assisted reproduction: a state of the art. J. Assisted Reprod. Genet. 28:119-128.

HAMMOND, J., JR. (1949). Recovery and culture of tubal mouse ova. Nature 163: 28.

HO, Y., WIGGLESWORTH, K., EPPIG, J.J. and SCHULTZ, R.M. (1995). Preimplantation development of mouse embryos in KSOM: Augmentation by amino acids and analysis of gene expression. Molec. Reprod. Dev. 41: 232-238.

HSU, Y.C. (1972). Differentiation in vitro of mouse embryos beyond the implantation stage. Nature 239: 200-202.

HSU, Y.C. (1973). Differentiation in vitro of mouse embryos to the stage of early somite. Dev Biol 33: 403-411.

HSU, Y.C. (1978). In vitro Development of Whole Mouse Embryos beyond the Implantation Stage. In Methods in Mammalian Reproduction, (ed. DANIEL, J. C.). Academic Press, pp.229-245.
HSU, Y.C. (1979). In vitro development of individually cultured whole mouse embryos from blastocyst to early somite stage. Dev Biol 68: 453-461.

JENKINSON, E.J. and WILSON, I.B. (1970). In vitro support system for the study of blastocyst differentiation in the mouse. Nature 228: 776-778.

JOSWIG, A., GABRIEL, H.D., KIBSCHULL, M. and WINTERHAGER, E. (2003). Apoptosis in uterine epithelium and decidua in response to implantation: evidence for two different pathways. Reprod Biol Endocrinol 1: 44.

KOOT, Y.E., TEKLENBURG, G., SALKER, M.S., BROSENS, J.J. and MACKLON, N.S. (2012). Molecular aspects of implantation failure. Biochim Biophys Acta 1822: 1943-1950.

LATOS, P.A. and HEMBERGER, M. (2016). From the stem of the placental tree: trophoblast stem cells and their progeny. Development 143: 3650-3660.

LAWITTS, J.A. and BIGGERS, J.D. (1993). [9] Culture of preimplantation embryos. In Guide to Techniques in Mouse Development, pp.153-164.

LEESE, H.J. (2012). Metabolism of the preimplantation embryo: 40 years on. Reproduction 143: 417-427.

LI, D.K. (2003). Exposure to non-steroidal anti-inflammatory drugs during pregnancy and risk of miscarriage: population based cohort study. Brit. Med. J. 327:368-370.

LINDENBERG, S. (1991). 1 Ultrastructure in human implantation: Transmission and scanning electron microscopy. Baillière Clin. Obstet. Gynaecol. 5: 1-14.

LINDENBERG, S., HYTTEL, P., LENZ, S. and HOLMES, P.V. (1986). Ultrastructure of the early human implantation in vitro. Human Reprod. 1: 533-538.

LINDENBERG, S., NIELSEN, M.H. and LENZ, S. (1985). In vitro Studies of Human Blastocyst Implantation. Ann. New York Acad. Sci. 442: 368-374.

LUO, Z.-X., YUAN, C.-X., MENG, Q.-J. and JI, Q. (2011). A Jurassic eutherian mammal and divergence of marsupials and placentals. Nature 476: 442-445.

MA, H., MARTI-GUTIERREZ, N., PARK, S.-W., WU, J., LEE, Y., SUZUKI, K., KOSKI, A., JI, D., HAYAMA, T., AHMED, R. et al., (2017). Correction of a pathogenic gene mutation in human embryos. Nature 548: 413-419.

MOLOTKOV, A., MAZOT, P., BREWER, J.R., CINALLI, R.M. and SORIANO, P. (2017) Distinct Requirements for FGFR1 and FGFR2 in Primitive Endoderm Development and Exit from Pluripotency. Dev Cell 41: 511-526 e4

MOR, G., CARDENAS, I., ABRAHAMS, V. and GULLER, S. (2011). Inflammation and pregnancy: the role of the immune system at the implantation site. Ann. New York. Acad. Sci. 1221: 80-87.

MORRIS, S.A., GREWAL, S., BARRIOS, F., PATANKAR, S.N., STRAUSS, B., BUTTERY, L., ALEXANDER, M., SHAKESHEFF, K.M. and ZERNICKA-GOETZ, M. (2012a). Dynamics of anterior-posterior axis formation in the developing mouse embryo. Nat Commun 3: 673.

MORRIS, SAMANTHAA., GUO, Y. and ZERNICKA-GOETZ, M. (2012b). Developmental Plasticity Is Bound by Pluripotency and the Fgf and Wnt Signaling Pathways. Cell Reports 2: 756-765.

MUNEOKA, K., WANEK, N. and BRYANT, S.V. (1986). Mouse embryos develop normallyExo utero. J. Exp. Zool. 239: 289-293.

NANCY, P., TAGLIANI, E., TAY, C.S., ASP, P., LEVY, D.E. and ERLEBACHER, A. (2012). Chemokine gene silencing in decidual stromal cells limits $T$ cell access to the maternal-fetal interface. Science 336: 1317-1321.

NIAKAN, K.K. and EGGAN, K. (2013). Analysis of human embryos from zygote to blastocyst reveals distinct gene expression patterns relative to the mouse. Dev Biol 375: 54-64

NISHIOKA, N., INOUE, K., ADACHI, K., KIYONARI, H., OTA, M., RALSTON, A., YABUTA, N., HIRAHARA, S., STEPHENSON, R.O., OGONUKI, N. et al., (2009). The Hippo signaling pathway components Lats and Yap pattern Tead4 activity to distinguish mouse trophectoderm from inner cell mass. Dev Cell 16: 398-410.

NOLI, L., DAJANI, Y., CAPALBO, A., BVUMBE, J., RIENZI, L., UBALDI, F.M., OGILVIE, C., KHALAF, Y. and ILIC, D. (2015). Developmental clock compromises human twin model created by embryo splitting. Human Reprod. 30: 2774-2784. (doi:10.1093/humrep/dev252)

O'LEARY, M.A., BLOCH, J.I., FLYNN, J.J., GAUDIN, T.J., GIALLOMBARDO, A., GIANNINI, N.P., GOLDBERG, S.L., KRAATZ, B.P., LUO, Z.X., MENG, J. et al., (2013a). The Placental Mammal Ancestor and the Post-K-Pg Radiation of Placentals. Science 339: 662-667.

O'LEARY, T., HEINDRYCKX, B., LIERMAN, S., VAN BRUGGEN, D., GOEMAN, J.J., VANDEWOESTYNE, M., DEFORCE, D., DE SOUSA LOPES, S.M.C. and DE SUTTER, P. (2012). Tracking the progression of the human inner cell mass during 
embryonic stem cell derivation. Nature Biotech. 30: 278-282.

O'LEARY, T., HEINDRYCKX, B., LIERMAN, S., VAN DER JEUGHT, M., DUGGAL, G., DE SUTTER, P. and CHUVA DE SOUSA LOPES, S.M. (2013b). Derivation of human embryonic stem cells using a post-inner cell mass intermediate. Nature Protocols 8: 254-264.

O'RAHILLY, R., MÜLLER, F. and STREETER, G.L. (1987). Developmental stages in human embryos: including a revision of Streeter's "Horizons" and a survey of the Carnegie Collection. Carnegie Institution of Washington.

OKAE, H., TOH, H., SATO, T., HIURA, H., TAKAHASHI, S., SHIRANE, K., KABAYAMA, Y., SUYAMA, M., SASAKI, H. and ARIMA, T. (2018). Derivation of Human Trophoblast Stem Cells. Cell Stem Cell 22: 50-63.e6.

PILISZEK, A., KWON, G.S. and HADJANTONAKIS, A.K. (2011). Ex utero culture and live imaging of mouse embryos. Methods Mol Biol 770: 243-257.

RAYON, T., MENCHERO, S., NIETO, A., XENOPOULOS, P., CRESPO, M., COCKBURN, K., CANON, S., SASAKI, H., HADJANTONAKIS, A.K., DE LAPOMPA, J.L. et al., (2014). Notch and hippo converge on Cdx2 to specify the trophectoderm lineage in the mouse blastocyst. Dev Cell 30: 410-422.

RIVERA-PÉREZ, J.A., JONES, V. and TAM, P.P.L. (2010). Culture of Whole Mouse Embryos at Early Postimplantation to Organogenesis Stages. In Guide to Techniques in Mouse Development, Part A: Mice, Embryos, and Cells, 2nd Edition, pp.185-203.

ROSSANT, J. and TAM, P.P.L. (2017). New Insights into Early Human Development: Lessons for Stem Cell Derivation and Differentiation. Cell Stem Cell 20: 18-28.

SHAHBAZI, M.N., JEDRUSIK, A., VUORISTO, S., RECHER, G., HUPALOWSKA, A., BOLTON, V., FOGARTY, N.M.E., CAMPBELL, A., DEVITO, L.G., ILIC, D. et al., (2016). Self-organization of the human embryo in the absence of maternal tissues. Nature Cell Biol. 18: 700-708.

STEELE, C.E. and NEW, D.A. (1974). Serum variants causing the formation of double hearts and other abnormalities in explanted rat embryos. J Embryol Exp Morphol 31: 707-719.

STEPTOE, P.C., EDWARDS, R.G. and PURDY, J.M. (1971). Human blastocysts grown in culture. Nature 229: 132-133.

STOWER, M.J. and SRINIVAS, S. (2018). The Head's Tale: Anterior-Posterior Axis Formation in the Mouse Embryo. In Cell Fate in Mammalian Development, pp.365-390.

SURVEYOR, G.A., GENDLER, S.J., PEMBERTON, L., DAS, S.K., CHAKRABORTY, I., JULIAN, J., PIMENTAL, R.A., WEGNER, C.C., DEY, S.K. and CARSON, D.D. (1995). Expression and steroid hormonal control of Muc-1 in the mouse uterus. Endocrinol. 136: 3639-3647.
TAM, P.P. (1998). Postimplantation mouse development: whole embryo culture and micro-manipulation. Int J Dev Biol 42: 895-902.

TANG, W.W.C., KOBAYASHI, T., IRIE, N., DIETMANN, S. and SURANI, M.A. (2016). Specification and epigenetic programming of the human germ line. Nature Reviews Genet. 17: 585-600.

UFER. (2011). The roles of glutathione peroxidases during embryo development. Front. Molec. Neurosci. doi: 10.3389/fnmol.2011.00012

VESTWEBER, D. and KEMLER, R. (1984). Rabbit antiserum against a purified surface glycoprotein decompacts mouse preimplantation embryos and reacts with specific adult tissues. Exp. Cell Res. 152: 169-178.

VIJAYAKUMAR, R., SIMONI, J., NDUBISI, B., DELEON, F. and HEINE, W. (2009). Mouse Embryo Growth in Different Culture Media: Selection of a Medium for Quality Control Cross-Testing of Human in vitro Fertilization Conditions. Archives of Andrology 19: 149-158.

WAMAITHA, S.E. and NIAKAN, K.K. (2018). Human Pre-gastrulation Development Curr Top Dev Biol 128: 295-338.

WHITTEN, W.K. (1956). Culture of tubal mouse ova. Nature 177: 96

WHITTEN, W.K. (1971). Nutrient Requirements for the Culture of Preimplantation Embryos in Vitro. In Schering Symposium on Intrinsic and Extrinsic Factors in Early Mammalian Development, Venice, April 20 to 23, 1970, pp.129-141.

WHITTINGHAM, D.G. (1971). Culture of mouse ova. J Reprod Fertil Suppl 14: 7-21.

WICKLOW, E., BLIJ, S., FRUM, T., HIRATE, Y., LANG, R.A., SASAKI, H. and RALSTON, A. (2014). HIPPO pathway members restrict SOX2 to the inner cell mass where it promotes ICM fates in the mouse blastocyst. PLoS Genet 10: e1004618.

WOLSTENHOLME, G.E.W. and O'CONNOR, M. (1965). Ciba Foundation Symposium - Preimplantation Stages of Pregnancy.

WU, Q., TEKLENBURG, G., WEIMAR, C.H.E., FAUSER, B.C.J.M., MACKLON, N., GEIJSEN, N., HEIJNEN, C.J., CHUVADE SOUSALOPES, S.M. and KUIJK, E.W. (2012). Cell Lineage Specific Distribution of H3K27 Trimethylation Accumulation in an In vitro Model for Human Implantation. PLOS ONE 7(3): e32701. (doi:10.1371/ journal.pone.0032701).

WU, T.C., WAN, Y.J. and DAMJANOV, I. (1981). Positioning of inner cell mass determines the development of mouse blastocysts in vitro. J Embryol Exp Morphol 65: 105-117.

YANEZ, L.Z. and CAMARILLO, D.B. (2017). Microfluidic analysis of oocyte and embryo biomechanical properties to improve outcomes in assisted reproductive technologies. MHR: Basic Sci. Reprod. Med. 23: 235-247.

ZERNICKA-GOETZ, M. and BEDZHOV, I. (2015). Media and methods for culturing embryos and stem cells. In GB2517194A, ed.: Cambridge Enterprise Limited. 


\section{Further Related Reading, published previously in the Int. J. Dev. Biol.}

Successful whole embryo culture with commercially available reagents

Hannah C. Glanville-Jones, Ngai Woo and Ruth M. Arkell

Int. J. Dev. Biol. (2013) 57: 61-67

https://doi.org/10.1387/ijdb.120098ra

Postimplantation mouse development: whole embryo culture and micro-manipulation P P Tam

Int. J. Dev. Biol. (1998) 42: 895-902

http://www.intjdevbiol.com/web/paper/9853819

Reflections on the culture of the preimplantation embryo.

J D Biggers

Int. J. Dev. Biol. (1998) 42: 879-884

http://www.intjdevbiol.com/web/paper/9853817

Egg culture: the foundation

R E Hammer

Int. J. Dev. Biol. (1998) 42: 833-839

http://www.intjdevbiol.com/web/paper/9853812

A review of the contribution of whole embryo culture to the determination of hazard and risk in teratogenicity testing

W S Webster, P D Brown-Woodman and H E Ritchie

Int. J. Dev. Biol. (1997) 41: 329-335

http://www.intjdevbiol.com/web/paper/9184342

Investigations into mechanisms of amino acid supply to the rat embryo using wholeembryo culture

D A Beckman, J B Lloyd and R L Brent

Int. J. Dev. Biol. (1997) 41: 315-318

http://www.intjdevbiol.com/web/paper/9184340

The evaluation of developmental toxicity of chemicals exposed occupationally using whole embryo culture

S F Zhao, X C Zhang, L F Zhang, S S Zhou, F Zhang, Q F Wang, Y L Wang and Y S Bao Int. J. Dev. Biol. (1997) 41: 275-282

http://www.intjdevbiol.com/web/paper/9184335
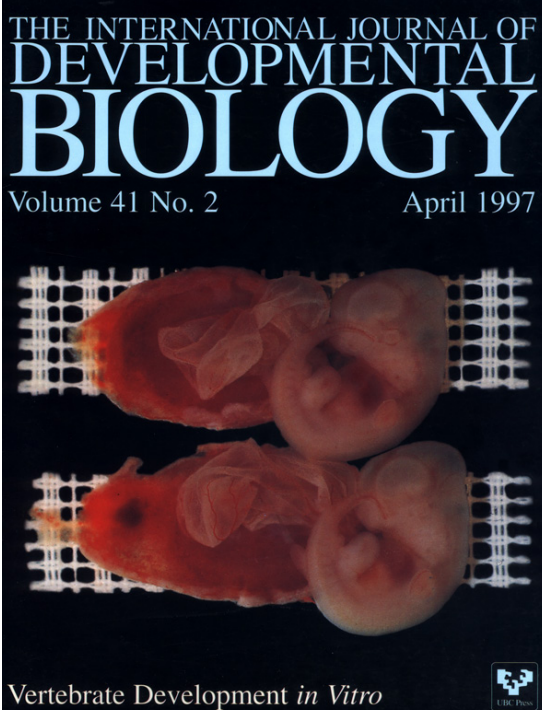

5 yr ISI Impact Factor $(2016)=2.421$
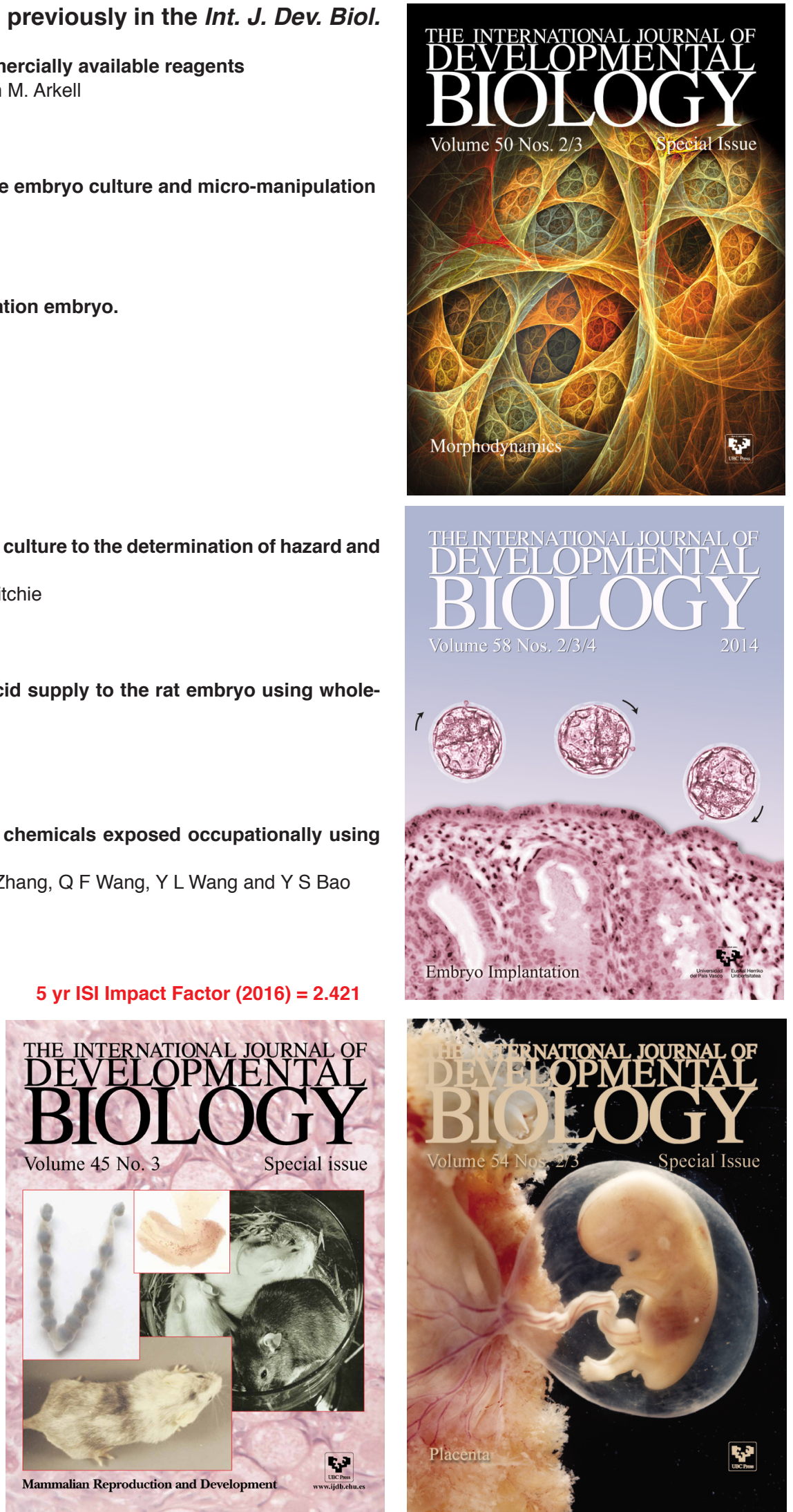